\title{
EL DERECHO DE LA LENGUA ${ }^{1}$
}

\author{
DIEGO VALADÉS \\ Director del Instituto de Investigaciones Jurídicas \\ Universidad Nacional Autónoma de México
}

\author{
SUMARIO \\ I. El problema. \\ II. Lengua y Constitución. \\ III. La muerte de las lenguas. \\ IV. Defensa jurídica de las lenguas.
}

\section{EL PROBLEMA}

Diversas estimaciones sitúan entre cinco mil y siete mil el número de lenguas que se hablan en el mundo ${ }^{2}$. Empero, si las fuentes difieren en cuanto a la cifra aproximada de las lenguas existentes, se tienen mejor identificadas las que se encuentran en proceso de extinción. Con algunas variaciones menores entre las fuentes, se estima que cada dos semanas en promedio muere una lengua. De seguir este ritmo, al terminar el siglo habrán desaparecido alrededor de 2.500 lenguas. Una merma tan cuantiosa del patrimonio lingüístico de la humanidad, en sólo cien años, es una catástrofe cultural. Además, desde una perspectiva constitucional, este fenómeno representa una amenazadora regresión.

Me explicaré. Hay muchos equívocos relacionados con el concepto tradicional de democracia. No me detendré a examinarlos, pero el más común consiste en asociar la democracia con el poder de la mayoría. En realidad, las categorías cuantitativas no representan una garantía para las ideas de justicia, de

1 El presente texto es parte del Discurso de Ingreso del autor en la Academia Mexicana de la Lengua el 25 de agosto de 2005.

2 Ethnoloque. Languages of the World. Dallas SIL, 2005, pp. 23 y ss., sitúa la cifra en 7.299. Los cálculos, sin embargo, varían. V.g. Andrew DALBY (Languaje in Danger, Londres, Penguin 2002, p. ix), sitúa la cifra en cinco mil. 
equidad, de libertad o de seguridad jurídica que cada miembro de la comunidad política sustente, intuya o anhele alcanzar. La mayoría puede ser opresora, de la misma manera que la minoría puede resultar liberadora. Ante esas aparentes paradojas, hay que atender a las regularidades, y éstas indican que la libertad se encuentra mejor garantizada cuando el gobierno es determinado por la mayoría, pero se trata de una tendencia, no de una constante inalterable.

El aforismo de la democracia "como el gobierno del pueblo, por el pueblo y para el pueblo", que A. Lincoln (1863), sin hacer mención de la fuente, tomó de S. Stuart Mill ${ }^{3}$ es sólo un constructo, no un axioma político ni jurídico. Expresiones cercanas a ese tipo de gobierno sólo se ha registrado en muy limitados casos; en la polis, si hacemos abstracción de los esclavos; en los falansterios, si aceptamos que alguna vez funcionaron; en los cantones, hasta donde la complejidad social lo permite, y en pocos ejemplos más.

Para corregir los defectos de la democracia mayoritaria, los griegos adoptaron diversos correctivos. Uno, el ostracismo, que permitía conjurar la tiranía del más popular ${ }^{4}$, otro, el sorteo, que ponía manos al azar, y no del voluntarismo, determinar la titularidad de las magistraturas. ${ }^{5}$ Cuando la democracia dejó de funcionar, se aplicaron otras reglas para eludir las luchas por el poder.

En Roma fue ideado otro mecanismo, practicado durante la monarquía y muchas veces también bajo el imperio: el predecesor designaba al sucesor. Esto, que hoy parece recordamos un capítulo, extenso, del acaecer histórico mexicano, fue saludable en la antigüedad. El señalamiento del sucesor lo hacía el príncipe para evitar conflictos entre quienes le sobrevivían. Esto era especialmente importante en sociedades cuya expansión suponía la presencia de una élite castrense. El enfrentamiento entre dirigentes armados podía afectar la integridad territorial del Estado y debilitar su capacidad de reacción ante ataques provenientes del exterior. Además, el autor de la sucesión no era sustituido en vida, por lo que no cabía la perpetuación en el poder, su decisión sólo tenía efectos póstumos.

Más tarde, en la Edad Media, proliferaron las dinastías hereditarias. Para justificarlas, hubo incluso que urdir y propalar la especie de que los monarcas tenían la facultad de hacer milagros. ${ }^{6}$ Estos procedimientos selectivos auparon a muchos monstruos, pero de tanto en tanto también franquearon las puertas del poder a personajes admirables.

3 Considerations on Representative Goverment (1861), VII.

4 Le fue aplicado, por lo menos, a Clístenes (507), Hiparlo (487), Megacles (486), Kallias (485), Xantipo (484), Kalixenos (483), Arístides (482), Themistocles (471), Cimón (461), Alcibíades (460), Tucidides (443), Hiperbolos (417), Véase Finley, M.I. Polititics in the Ancient World, Nueva Cork, Cambridge University Press, 1983, pp. 55 y ss.

5 Cfr. DARETE, Rodolphe, La science du droit en Gréce, París, Larose \& Corcel, 1983, pp. 53 y ss.; LANG, Mabel The Atenian Citizen, Princeton, The American School of Classics Studies, 1987, pp. 8 y ss.; MANIN, Bernard, Los principios del gobierno representative, Madrid, Alianza, 1998, pp. 19 y ss.

6 Veáse el notable estudio de Marc BLOCH, Teb Royal Touch, Monarchy and Miracles in France and England, Nueva York, Dorset, 1961. El autor menciona que ya a Vespasiano se le había atribuido la realización de milagros (p. 13), pero la práctica se hizo frecuente, particularmente en la curación de escrófula a partir de los siglos X-XI (pp. 28 y ss). 
Las patologías del poder han sido más frecuentes, profundas y dañosas en los sistemas oligárquicos que en los poliárquicos, pero esto no excluye el peligro potencial de una tiranía mayoritaria. Díganlo, si no, Cromwelly Robespierre. Para sortear esa amenaza fueron construyéndose los sistemas constitucionales.

El constitucionalismo ha entrado ya en su tercera centuria, y registra cambios progresivos. Las Constituciones escritas y aceptadas por los monarcas fueron un avance de peso. Luego vinieron los derechos fundamentales y sus garantías de observancia; los sistemas representativos se hicieron paulatinamente más porosos; los procedimientos electorales más universales y seguros; los controles políticos más eficaces; los organismos jurisdiccionales más autónomos e imparciales. Todos estos instrumentos son de alta sensibilidad y tienen que ser afinados de continuo, porque de su uso o desuso, resultan desgastes, fracturas y atrofias.

Las soluciones viejas se han transformado en los problemas nuevos. Hoy, al cabo de una larga andadura, podemos respirar aliviados sólo cuando nos contrastamos con el pasado; pero a veces aflige advertir lo que se nos viene por delante. En el mundo ya no dominan los monarcas absolutos, ni los caudillos militares; a su vez las asambleas domeñadas, los jueces de consigna y los fraudes electorales dejaron de ser preceptivos. Hasta aquí las cuentas son positivas; pero ahora no quedan pretextos para encarar lo que llevamos siglos posponiendo: la exclusión social. Este fenómeno, cuya atención se ha ido dejando siempre para después, se hace ostensible cuando otros pliegues del poder se han ido alisando. Ya no restan excusas para mantener la rutina del olvido.

Por eso la democracia de nuestros días no es sólo el gobierno de la mayoría; es el gobierno de todos. Los instrumentos constitucionales modernos confieren unos ciertos derechos para tomar decisiones a la mayoría, pero nunca a expensas de los derechos que también asisten a las minorías. En un sistema constitucional nadie tiene vedado el acceso al poder; varían las atribuciones, según el apoyo electoral de que se disponga, pero las minorías en ningún caso carecen de influencia en las determinaciones colectivas. La democracia contemporánea confiere a las minorías derechos que antes no tuvieron. Esta es nuestra revolución cultural democrática; es la pequeña revolución, porque se ha hecho sin efusión de sangre, sin sacudimientos violentos, sin estereotipos, sin premura, incluso sin adalides, protagonizada por los colectivos nacionales merced a una singular convergencia que la comunicación, otro fenómeno cultural, ha hecho posible.

La revolución conceptual de nuestro tiempo resulta de la propagación de voces sencillas pero convincentes. En todos los sistemas que adoptan los principios del Estado constitucional, los derechos de las minorías han adquirido una importancia creciente, como uno de los medios más adecuados para superar la exclusión.

La expresión más característica de la exclusión tiene un contenido económico. Es comprensible, porque se trata de lo más lacerante y más fácilmente aprehensible. Decir que la mitad de un país vive en la pobreza, o que la mitad de la población mundial está desnutrida, tiene un efecto estremecedor; cuando 
se alude a las causas o a las consecuencias culturales de la exclusión, el impacto es sensiblemente inferior. Es comprensible. El tejido social presenta tantas desgarraduras, que las culturales parecen menos apremiantes. Lo que no se advierte es que, por la complejidad de la sociedad contemporánea, lo cultural también es prioritario. El derecho, por ejemplo, es el factor sustantivo de la cohesión social, porque el derecho no es otra cosa que un producto de la cultura, y sin instrumentos jurídicos adecuados no habría forma de conjurar la exclusión.

Es aquí donde entra el capítulo de las lenguas. Es inevitable que algunas lenguas mueran, pero es inadmisible que queden sin registro; que se les niegue al menos el derecho a un certificado de defunción. Las lenguas, que hacen la diferencia entre los hombres y el resto de las especies animales, no pueden ser dejadas a su suerte sin, con ello, acentuar la naturaleza excluyente que todavía presentan una buena parte de los sistemas constitucionales del orbe.

Como patrimonio cultural de las sociedades, como símbolo de la identidad de los grupos y de los individuos, el derecho de las lenguas, y su garantía de observancia, es un peldaño más que el constitucionalismo debe ascender.

\section{LENGUA Y CONSTITUCIÓN}

Una de las características del constitucionalismo contemporáneo es el reconocimiento tanto de los derechos culturales como de los derechos de las minorías. Actualmente, de 180 Constituciones, sólo 22 no contienen referencias a las lenguas. Dos de éstas corresponden a Estados de nuestro hemisferio: Chile y Uruguay. La omisión uruguaya no resulta significativa, si se tiene en cuenta que en ese país sólo están reportadas dos lenguas, incluido el español, pero sí en Chile, donde en las últimas décadas se han extinguido dos lenguas, y otras dos de las pocas restantes ya son habladas por menos de cien personas.

En numerosos casos son las leyes ordinarias las que determinan cual es la lengua oficial, por lo que son escasos los Estados que carecen por completo de definiciones legales sobre la materia. Sin embargo, en virtud de la tendencia, cada vez más pronunciada, en cuanto a tutelar los derechos de los grupos minoritarios, en especial los de relevancia cultural, las Constituciones de nuevo cuño van sumándose a la lista de las que sí se ocupan de la materia.

Sobre ese tema existe una gran variedad de normas que, no obstante, se pueden sistematizar en tres grandes corrientes: las que reconocen como lengua oficial la que prevalece en el país; las que admiten la diversidad lingüística pero dejan que cada una se desarrolle de manera más o menos espontánea, y las que adoptan compromisos estatales en cuanto a la difusión, preservación y desarrollo de las lenguas minoritarias.

En el primer caso están las Constituciones de Arabia Saudita, Egipto, Filipinas, Francia, Letonia, Lituania, Noruega, Polonia, Portugal y Rumanía, por ejemplo. También figuran en este grupo Brasil, Cuba, Honduras - donde el Estado se compromete a proteger la pureza del español y a "incrementar" su en- 
señanza- y Panamá. En ninguno de estos países la Constitución hace referencia a los derechos lingüísticos de los grupos minoritarios. El caso brasileño es llamativo, si se tiene en cuenta que apenas hace dos décadas tenía censadas 235 lenguas, de las que ya se han extinguido 47, y otras 25 correrán la misma suerte dentro de muy poco tiempo.

La situación de India es peculiar. Se establece (arts. 343 y ss.) como lengua oficial el hindi, aunque se adoptó una especie de plazo de tolerancia para que el inglés siguiera como lengua oficial durante los primeros quince años de vigencia de la Constitución de 1950. Una reforma posterior ha permitido que el Parlamento amplíe el plazo, y que el inglés se utilice en los debates parlamentarios y en las resoluciones jurisdiccionales. Además, conforme al artículo 29, se estatuye la protección de los intereses de las minorías, que incluye el derecho a utilizar y conservar su lengua. En materia lingüística la regulación constitucional hindú, es junto a la sudafricana, la más detallada de cuantas existen. Entre otras cosas, la Constitución dispone (art. 350 B) la designación de un alto comisionado presidencial para atender los problemas lingüísticos de las minorías.

La diversidad lingüística también es reconocida en Austria, Bélgica, Eslovenia, Finlandia, Georgia, Haití, Irlanda, Malasia y Suiza. Además, en este grupo llama la atención el caso de Singapur, donde son de uso parlamentario el malayo, el mandarín, el tamil y el inglés. Otro caso singular de diversidad es el de Croacia. Aunque en la Constitución de este país se establece como lengua oficial el croata, escrito en caracteres latinos, se admiten la grafía cirílica y otras que se practiquen en las diversas localidades del país.

También hay que destacar el caso de China (art. 4. ${ }^{\circ}$ ), donde no hay una lengua oficial nacional, y el problema del multilingüismo fue resuelto reconociendo que todas las nacionalidades interiores están en libertad de usar y desarrollar sus propias lenguas, escritas y habladas, así como de preservarlas o reformarlas según su propia decisión. En este caso el Estado nacional no asume responsabilidad alguna y deja a su suerte a cada grupo lingüístico. No se prevé que desaparezca alguna de las más de cincuenta lenguas habladas en China, aunque sí es claro el desarrollo asimétrico entre ellas, como resultado de las diferencias económicas y culturales regionales.

En Austria (art. 8. $^{\circ}$ ) se declara lengua oficial al alemán, "Sin perjuicio de los derechos que la ley federal reconozca a las minorías lingüísticas». La solución es muy práctica, porque la Constitución no adopta reglas minuciosas, pero sí orienta el contenido de la ley de la materia. A diferencia del caso austriaco, en Bélgica (art. 4o.) la norma suprema ha tenido que entrar en mayores detalles. Las tensiones entre los grupos nacionales han sido más pronunciadas, y la Constitución ha definido directamente las cuatro regiones lingüísticas: la francesa, la holandesa, la alemana, y la a su vez bilingüe de Bruselas. La norma belga es de una rigidez extrema, pues sólo puede ser modificada si el grupo parlamentario que representa la región lingüistica acepta cualquier posible reforma por, al menos, dos terceras partes de sus integrantes.

Las normas constitucionales nicaragüenses (art. 11) y peruana (art. 48) están en una posición más abierta. En ambos casos el idioma oficial es el español 
y se estatuye que las lenguas vernáculas tienen carácter oficial en las zonas donde predominen. Aquí el Estado sólo tiene una obligación pasiva, en cuanto a consentir el uso de las lenguas locales con carácter oficial, pero no las incorpora al patrimonio cultural nacional. En Colombia (art. 10), donde es oficial el castellano, se adopta una estructura semejante, pero se agrega que la enseñanza impartida en las comunidades con tradiciones lingüísticas propias, debe ser bilingüe.

El grupo de Constituciones que, además de la diversidad, establece compromisos para el Estado en cuanto a adoptar medidas positivas para los derechos lingüísticos, es relativamente reducido, aunque sus aportes son significativos. En este ámbito sobresalen los países iberoamericanos, aunque no el nuestro.

La corriente más importante está representada por Costa Rica, cuya Constitución (art. 78) establece que la lengua oficial es el español, pero agrega que el Estado es responsable de velar por el mantenimiento y cultivo de las lenguas indígenas. Ecuador (art. 1) adoptó una fórmula muy sugerente: "El Estado respeta y estimula el desarrollo de todas las lenguas de los ecuatorianos". A continuación señala que la lengua oficial es el castellano, pero añade que el quichua, el shuar "y los demás idiomas ancestrales" son de uso oficial para los pueblos indígenas.

En El Salvador (art. 62), la lengua oficial también es el castellano, con relación al cual el gobierno tiene la obligación de velar por su conservación y enseñanza; en cuanto a las lenguas autóctonas, las declara integrantes del patrimonio cultural y objeto de preservación, difusión y respeto. Otro tanto se hace en Guatemala (art. 143) y en Venezuela (art. 9) donde el idioma oficial es el español, y se declara patrimonio cultural a las lenguas vernáculas.

$\mathrm{Al}$ incorporar a una lengua al patrimonio cultural de una nación se establece el compromiso estatal de preservarla, y la preservación no se limita a mantener una cosa en el estado que guarde, que bien pudiera ser declinante; conservar también supone realizar las acciones necesarias para que mantenga su vigencia y, en lo posible, recupere su esplendor. Cuando el objeto tutelado es una lengua viva, la obligación consiste en alentar su vitalidad, con los poderosos instrumentos que la educación y la difusión ofrecen.

España, Rusia y Sudáfrica figuran, asimismo, entre los Estados que han hecho de la diversidad lingüística un paradigma. El carácter oficial de las lenguas locales, y su naturaleza de patrimonio cultural, es reconocido por la Constitución española (art. 3o.); la rusa (art. 68), autoriza a las repúblicas federadas para que establezcan libremente sus lenguas oficiales, y además, declara la responsabilidad del Estado nacional en cuanto a promover el estudio y desarrollo de las lenguas nativas.

El caso sudafricano merece atención especial, porque, como India, contiene el más amplio tratamiento en vigor en el mundo, con relación a los derechos lingüísticos. Diversas secciones (6, 9, 29, 30, 31, 35, 185, 186 y 215) de la Constitución, adoptada el 8 de mayo de 1996, se ocupan de esos derechos y ofrecen un panorama de la considerable amplitud que puede alcanzar esa 
nueva vertiente jurídica. En primer término se advierte que las lenguas vernáculas han sido históricamente desdeñadas y que el Estado constitucional debe adoptar medidas positivas para elevar el estatus y promover el uso de esas lenguas. El régimen jurídico de las lenguas es objeto de protección por parte del Estado nacional, de las provincias que lo integran y de los municipios.

La posición constitucional sudafricana abre un nuevo horizonte para los derechos lingüísticos, porque además de la tutela de las lenguas nativas, extiende garantías a las cultivadas por otras minorías culturales, como la alemana, la griega, la portuguesa, la árabe, la hebrea y la hindú. Más aún, admite que, dentro de las posibilidades del Estado, las minorías tienen derecho a recibir educación en las instituciones públicas, en la lengua de su elección. La misma Constitución establece, como organismo del Estado, la Comisión para la Promoción y la Protección de los Derechos de las Comunidades Culturales, Religiosas y Lingüísticas.

Otro ejemplo digno de consideración es la ley de Lengua galesa. Esta Ley fue adoptada, en Gales, en 1993, con objeto de promover y facilitar el uso del galés. La Ley estableció que en los trámites administrativos y en las instancias jurisdiccionales, el inglés y el galés serían lenguas oficiales, sobre "bases de equidad". Para aplicar la Ley fue constituido un comité (Welsh Language Borrad) integrado por quince miembros, que además de adoptar las medidas administrativas que motivaron la Ley, puede constituir fondos, provenientes de donaciones y fideicomisos, destinados a apoyar a la lengua Gales. Las acciones del comité están dirigidas a la planificación de la enseñanza y difusión de la lengua, al adiestramiento de profesores, a la supervisión de los servicios públicos, en especial los de salud y educación, y a la relación con los medios de comunicación, por lo que respecta a la protección y promoción de la lengua. A lo largo de los años de actividad, la inicial actitud de reserva, incluso de escepticismo, ha dejado su lugar a un amplio reconocimiento por las tareas que el comité ha realizado, haciendo de esta Ley un ejemplo.

En el orden internacional, además de la Declaración Universal sobre diversidad cultural, adoptada por la UNESCO en 2001, existen tres grandes áreas, África, América y Europa, donde diversos instrumentos hacen referencia a los derechos lingüísticos. Todos los acuerdos regionales postulan el derecho de las comunidades a la preservación de sus lenguas originales.

\section{LA MUERTE DE LAS LENGUAS}

Hasta aquí se ha visto un panorama muy general del régimen jurídico de las lenguas. Empero, hay un tema que no ha sido abordado por las normas nacionales ni por las internacionales: el riesgo de extinción de las lenguas, y la obligación de reducir esa amenaza al mínimo posible. El PEN club internacional, así como otros organismos no gubernamentales, que incluyen fundaciones e instituciones académicas, han aludido al acelerado proceso de desaparición de las lenguas. 
Hay un mecanismo defensivo que se llama indiferencia, merced al cual nos habituamos con prontitud a las condiciones más adversas y acabamos por considerarlas parte de nuestra normalidad. Por eso, no nos conmovemos por saber que cada hora fallecen, de inanición, mil quinientos seres humanos; que cada tres minutos disminuye la diversidad biológica por la pérdida de una especie; que cada día es destruida una extensión de bosques tropicales equivalente al área del Distrito Federal. En cuanto a las lenguas; se calcula, como se dijo más arriba, que cada dos semanas muere una. ${ }^{7}$ Cuando este siglo concluya habremos perdido un tercio y la mitad del patrimonio lingüístico de la humanidad, según el censo de lenguas existente que se maneje.

El reporte Ethnologue localiza 290 lenguas en México $^{8}$, entre las que es inminente la extinción del kiliwa, en Baja California, del matlatzinca, en el Estado del México, del zapoteco de Mixtepec, y del zoque, en Tabasco. El panorama de las antiguas lenguas mexicanas es todavía más desolador allende nuestras fronteras. De las cerca de cien lenguas que llegaron a ser identificadas en California ${ }^{9}$, actualmente 36 son recordadas por ancianos, 17 tienen menos de cinco hablantes y el resto ha desaparecido. Este proceso de extinción no ha sido objeto de nuestra atención.

Se estima que la población mexicana de California, en 1845, era superior a los ciento cincuenta mil habitantes; en los primeros diez años de la anexión por Estados Unidos fueron presumiblemente aniquilados cien mil. Con ellos desaparecieron sus lenguas. Nunca pedimos cuentas; nunca merecimos explicaciones. El Tratado de Guadalupe autorizaba al gobierno estadounidense para "castigar y escarmentar" a las "tribus salvajes" y para "desalojar a los indios", cuando las condiciones de seguridad o de sanidad lo hicieran recomendable. El impacto demográfico y cultural de este Tratado fue devastador.

Nuestras lenguas ya habían sido acosadas desde mucho antes. El 17 de abril de 1770 el rey dictó una Real Cédula para que se tomaran las medidas necesarias para que "se extingan los diferentes idiomas que se usa en los mismos dominios y sólo se hable el castellano, como está mandado por repetidas leyes, reales cédulas y órdenes espedidas en el asunto". ${ }^{10}$

\section{DEFENSA JURÍDICA DE LAS LENGUAS}

Esta Academia es correspondiente de la Española; pero también es mexicana. Nuestro vehículo de expresión es el español, pero en punto a derechos,

7 Cfr. CRISTAL, David, Language Death, Cambridge, Cambridge University Press, 2005, pp. 68 y ss.

8 En este punto también una variación importante con relación a la información disponible. El Atlas de infraestructura cultural de México (México, CONACULTA, 2003, pp. 30 y ss), identifica sólo 62 lenguas. Este es el dato más confiable, en tanto que Ethnologue considera como lenguas las múltiples variantes de una sola lengua. No obstante esto, como en muchos casos la desaparición se está produciendo conforme a algunas de esas variantes, tomé el dato de Ethnologue para basar mi argumentación.

9 DALBY, Andrew, Language in Danger, Londres, Penguin, 2002, pp. 238 y ss.

10 Cfr. DUBLÁN y LOZANO, Legislación Mexicana, México, Imprenta del Comercio, 1876, t. I. p. 20. 
el que asiste a esta lengua concierne también a las demás. El derecho de la lengua es un capítulo axial de los derechos fundamentales contemporáneos. La maldición de Babel consistió en la incomunicación entre los hombres por su propensión a la idolatría, pero no condenaba su vocación por la cultura. ${ }^{11}$ La diversidad lingüística es una prueba, intrínsecamente elocuente, de la vitalidad cultural de la humanidad. Mutilar esa diversidad, o dejarla a su suerte, lesiona la naturaleza humana, porque afecta la identidad de las personas, aún cuando sólo sea de una porción numéricamente reducida.

Lo que el constitucionalismo ha hecho por la cultura es, precisamente, reconocer los derechos de las minorías y dar a los derechos culturales la misma jerarquía que los tradicionalmente reconocidos como fundamentales: la vida, la libertad y la seguridad jurídica. A partir de la segunda mitad del siglo anterior, y como respuesta a los actos de barbarie que segaron millones de vidas, las Constituciones acogieron y tutelaron un nuevo principio: el de la dignidad. La dignidad, en nuestro tiempo, es un valor ético que también tiene relevancia jurídica.

Ahora bien, de todos los fenómenos culturales, el que registra cambios más lentos es el Estado. En tanto que la velocidad de innovación de las ciencias y de las artes es vertiginosa, la renovación del Estado habitualmente se caracteriza por su parsimonia. Por eso es un espacio cultural donde todavía hay cabida, en ocasiones holgada, para los conservadores. Si además entendemos que el Estado y el derecho son dos formas de expresar la misma realidad, advertiremos hasta qué punto la pausada marcha de las instituciones puede verse sacudida merced a las pulsaciones más intensas del ámbito en el que actúan.

Resulta arduo superar la inercia de las instituciones y acelerar su ritmo. Solamente los grandes vendavales sociales generan un aleteo que lleva a esas instituciones a otros espacios; no siempre, claro, a los que se quisiera. La historia de las instituciones no es lineal; no hay una progresión ascendente, si así se le quisiera llamar. Sus cambios son más bien en zig-zag, por lo que hace a su contenido ideológico, y en altibajos, por lo que atañe a sus resultados.

Los preceptos del Estado se basan en un concepto relativamente simple: la jerarquía. Los cambios culturales que se registran en el constitucionalismo contemporáneo han sido, en buena medida, resultado de las fuertes demandas que proceden de los ámbitos académicos, los medios de comunicación, las organizaciones sociales que han proliferado; de los movimientos protagonizados por las minorías, de la desaparición del sistema colonial, de la supresión de sistemas totalitarios y la democratización de los autoritarios. Todo esto fue lo que, en el orden institucional, dejó la segunda posguerra mundial. Cinco décadas de profundos ajustes fueron aprovechados para imprimir otro rostro al Estado. Después de la Revolución Francesa, el Estado no había vivido tan profundos cambios.

11 Cfr. HYLAND, Richard, "Babel: a She'ur" en Morawetz, Tom, Law and Language, Darmouth, Ashgate, 2000, p. 32. 
El impulso no debe menguar. Ahora, para impedir que el Estado retorne a su ritmo pacato y retome su estilo críptico, la comunidad internacional ha dejado de ser sólo el escenario de las grandes burocracias y el territorio de las grandes corporaciones; es también el espacio donde los grupos sociales actúan, las personalidades se proyectan, los medios influyen y la cultura se expande. La mundialización, o globalización, comenzó como un fenómeno político y económico, pero paulatinamente se transforma en un proceso cultural.

Las lenguas tienen una oportunidad impar. Hay una constante que nos indica la subsistencia de las lenguas asociadas al poder. Después de todo, el derecho no es sino un conjunto de palabras con poder. La oficialización de las lenguas vernáculas es un fenómeno reciente, por lo que habrá que aguardar algo más para corroborar que su uso, constitucionalmente garantizado, haya tenido como efecto su perdurabilidad.

Ahora bien, hemos visto que sólo en algunos casos se dispone de instrumentos constitucionales para proteger las lenguas, y que los acuerdos internacionales todavía no reconocen el desafío de las que están en peligro. En el horizonte del tiempo, los reconocimientos nacionales del multilingüismo tendrán un efecto tutelar para la vida de las lenguas, pero podrían acortarse los pasos si se emprendieran acciones deliberadamente encaminadas a alcanzar esta meta.

Dos modalidades jurídicas se antojan recomendables: una, auspiciar la multiplicación de normas nacionales para considerar a las lenguas vernáculas como parte del patrimonio cultural, y desplegar en consecuencia un abanico de acciones encaminadas a su desarrollo. Otra, impulsar la suscripción de compromisos internacionales, mediante la ampliación de la Declaración Universal sobre Diversidad Cultural, de la UNESCO, para conjurar la degradación lingüística de la humanidad. No es menester ensanchar las burocracias internacionales; bastará con adoptar mecanismos que permitan impulsar y coordinar los esfuerzos de las instituciones nacionales, para generar un nuevo compromiso con la cultura.

Será imposible evitar la extinción de un elevado número de lenguas; pero de ellas podrán conservarse los registros que, a lo menos, perpetúen su memoria y permitan su estudio. Las instituciones educativas y de investigación tendrían que intensificar los estudios filológicos.

Hay experiencias análogas. En cuanto a las especies en peligro de extinción se han adoptado, con éxito, medidas jurídicas para protegerlas. En 1973, por ejemplo, Estados Unidos puso en vigor una ley en esa materia. Expresamente se reconoció que diversas variedades de animales y vegetales se encontraban en riesgo de desaparecer, como consecuencia de un crecimiento económico invasivo, y se resolvió estimular a las autoridades locales y municipales para emprender acciones que pusieran a resguardo esas especies; también fueron previstos estímulos para los particulares que ayudaran en esa tarea, y sanciones para quienes no respetaran las salvaguardas adoptadas. Con el propósito de salvar las especies en peligro de extinción, y con base en la ley, se puso en marcha un formidable programa de inversiones públicas para levantar inventarios, adquirir tierras, modificar vías de comunicación, regular el comer- 
cio, desarrollar técnicas reproductivas, adiestrar personal, organizar grupos de estudio, estructurar agencias oficiales y fideicomisos, además de alentar asociaciones civiles. Con una orientación análoga, en el ámbito internacional rige la Convención sobre Comercio Internacional de Especies en Peligro, suscrita en Washington, también en 1973. Es válido preguntar si las lenguas en extinción no merecen algo semejante.

Uno de los más importantes tratadistas de los derechos lingüísticos es Tove Skutnabb-Kangas. De acuerdo con su tesis, por otra parte ampliamente aceptada, una declaración universal de los derechos humanos lingüísticos debe garantizar, en el ámbito de cada individuo, la identidad con la lengua materna y el respeto por parte de terceros. Esto supone que cada persona reciba educación en su lengua materna y la pueda utilizar de manera oficial, o sea, en su vida de relación laboral y en su comunicación con las entidades públicas. Además, se debe disfrutar de la garantía de que ningún cambio relacionado con la lengua materna será compulsivo, y que se dispondrá de información completa sobre las consecuencias de cuantas opciones se ofrezcan en el largo plazo. ${ }^{12}$

Los derechos fundamentales son de naturaleza subjetiva; el problema está en determinar cuál es el significado del derecho subjetivo. En términos generales se ha entendido como un poder jurídico (Windscheid) o como un interés jurídicamente tutelado (Ihering). La polémica no se ha zanjado (Alexy) ${ }^{13}$ y siguen acumulándose argumentos que se acogen a la teoría de la voluntad, a la del interés, o a combinaciones de ambas.

El tema no puede ser pacífico, porque desde el punto de vista de un Estado constitucional, es válido preguntar, con relación a las minorías, si los derechos protegidos son sólo de esas minorías o son de la comunidad en general. En otras palabras, ¿los derechos de los zapotecos son sólo de los zapotecos, o son de todos los mexicanos? Si los derechos de igualdad, libertad y seguridad jurídica corresponden a la universalidad que conocemos como sociedad, ¿Por qué los derechos culturales deben ser de una colectividad restringida, o de un conjunto de colectividades a las que denominamos "minorías"?

Aquí quedan por resolver cuestiones delicadas, que afloran de manera especialmente llamativa cuando hablamos de los derechos lingüísticos. Preguntémonos, en esta Academia, si el interés de proteger el opata atañe sólo a las quince personas que todavía lo hablan, o a todos los mexicanos. Interroguémonos, también, si a los mexicanos únicamente nos concierne la protección normativa de las lenguas vernáculas nacionales, o también tenemos interés en el andoque, extinguido en Perú y presto a desaparecer en Colombia; o en el abnaki, apagándose en Canadá, por ejemplo.

12 SKUTNABB-KANGAS, Tove "The Scope of Linguistic Human rights", en PHILLIPSON, Robert (ed.) Rights to Language Equity, Power, and Education, estudios en honor de TOVE SKUTNABB-KANGAS, N. Jersey, Lawrence Erlbaum Associates, 2000, pp. 55 y ss.

13 Cfr. ALEXY, Robert, Teoría de los derechos fundamentales, Madrid, Centro de Estudios Constitucionales, 1997, pp. 178 y ss. 
El carácter subjetivo de los derechos lingüísticos no implica que sólo tengan como titulares a quienes se encuentran en una posición numéricamente inferior a la mayoría. Éste ha sido hasta ahora el criterio aplicado por la doctrina y seguido por los instrumentos nacionales e internacionales, pero será menester revisarlo. El constitucionalismo contemporáneo reconoce una nueva dimensión a los derechos de las minorías; en especial el derecho a no sufrir la opresión de la mayoría y, por los mismo, sus intereses deben ser tutelados, aunque no dispongan de la fuerza política suficiente para hacerles valer. Pero, en la suma de disposiciones constitucionales, no son distinguibles los derechos de los más y los derechos de los menos, porque todos los derechos constitucionales son de todos los destinatarios de la Constitución.

En esos términos, no se trataría del derecho lingüístico de un otomí frente al resto de los mexicanos, sino del derecho lingüístico de todos los mexicanos, que cada uno ejerce en los términos que resultan más satisfactorios para sus intereses, y más acordes con su elección cultural. De cierta manera, en este caso el derecho subjetivo participa de las características del poder jurídico y del interés jurídicamente protegido.

Si esto es así, podemos decir que el derecho lingüístico comprende todas las lenguas que se hablan en el territorio de un Estado, así la mayoría como las minorías. Esto contraría el concepto de neutralidad constitucional preconizado por Michael Waltzer, conforme al cual el Estado debe abstenerse de fijar criterios relacionados con la lengua, la historia y la literatura. Lo cual sólo es cierto en cuanto a que el Estado no puede imponer una posición dogmática a los gobernados sin violentar su naturaleza constitucional; por eso Kymlicka lo ha refutado al formular su tesis de la "cultura societaria", que tiene una connotación territorial y está representada precisamente por el lenguaje compartido. ${ }^{14} \mathrm{La}$ expresión no es pleonástica. La cultura es un fenómeno social, pero el profesor canadiense alude en este caso a la que es propia de grupos en particular o que identifica a determinadas instituciones sociales. El Diccionario de la lengua, de la Real Academia Española, define el adjetivo "Societario" como lo "perteneciente o relativo a las asociaciones, especialmente a las obreras". Quizá habría que ampliar el concepto académico, para que societario también comprenda a los grupos no organizados.

El concepto de derecho lingüístico está lejos de ser uniforme. Dora Pellicer, ${ }^{15}$ por ejemplo, lo identifica como propio de los pueblos habitualmente considerados minoritarios. Si los derechos religiosos fueran un referente, también podríamos verlos en su origen como una forma de proteger a las minorías; como una expresión de tolerancia. Pero en este punto los derechos se han extendido. Las normas en materia de creencias y convicciones protegen a todos

14 KYMLICKA, Hill, "Nation-Building and MInority Rights: Comparing West and East", Journal of Ethnic and Migration Studies, Nueva York, vol. 26, núm. 2, Routledge 2000, pp. 183 y ss.

15 "Derechos lingüísticos en México: realidad y utopía", documento de trabajo presentado con motivo del XX Congreso Internacional de la Latin American Studies Association, celebrado en Guadalajara, en abril de 1997. 
los creyentes, incluidos los que pertenecen a una religión mayoritaria, y a los que no profesan religión o credo alguno. Si los derechos religiosos y de creencias son aplicables a todos los habitantes del territorio de un Estado, en cuanto una expresión de respeto por las convicciones, no tiene por qué ocurrir de manera inversa en materia de lenguas, que también corresponden a la libertad de elegir.

La relación entre la mayoría y las minorías fue, inicialmente, un capítulo de la tolerancia. Ahora bien, la tolerancia, en materia lingüística no representa un gran avance, como ha mostrado recientemente Francesca Pou, ${ }^{16}$ porque no iguala las oportunidades entre quienes hablan diferentes lenguas. Si bien el Estado no debe alentar religión alguna, porque invadiría un espacio personalísimo, en materia de lenguas no puede abandonarlas a su suerte, porque dejaría una parte del patrimonio cultural sin la protección debida.

La política de la tolerancia indica una actitud pasiva, de no intromisión. Los derechos lingüísticos no lo son sólo de los grupos minoritarios. Los derechos culturales de los grupos minoritarios son de interés general, como todas las disposiciones que integran el sistema constitucional, con la peculiaridad de tener por titulares a quienes se encuentren en el supuesto que la misma norma prevé. Miguel Carbonell ha apuntado que se trata de un terreno polémico. ${ }^{17}$ Por la naturaleza de los destinatarios, son pocas las normas destinadas a ser aplicadas por la totalidad de los habitantes del territorio de un estado. Las causantes en materia fiscal, por ejemplo, serían "una minoría" si se les contrasta con la totalidad de la población; y cuando se adoptan medidas para proteger a la infancia, a la vejez, o a los afectados por los padecimientos que invalidan, se hace referencia a grupos demográficamente reducidos. No es en este sentido que se hace referencia a los derechos de las minorías, a menos que padezcan alguna forma de exclusión.

Los derechos culturales atañen a la población en general (como el acceso a los servicios educativos o la libertad de creación artística o de investigación), aunque por su naturaleza no sean ejercidos por la totalidad. ¿Qué se quiere decir, por tanto, cuando se alude a los derechos de las minorías? Esencialmente se hace referencia grupos sociales que padecen o han padecido alguna forma de exclusión, aunque esto no se reconozca, o se haga de manera velada. Miguel Carbonell utiliza el concepto de "derechos colectivos" para enmarcar el haz de normas atinentes a la protección de minorías. La expresión, como cualquier otra, es opinable, pero en este caso resuelve, de manera convencional, un problema terminológico que para muchos es difícilmente inteligible. Sea que hablemos de "derechos colectivos", o de "derechos societarios", sabemos que estamos aludiendo a los que corresponden a grupos humanos con derechos preteridos.

16 "Contra la lengua invisible. Un discurso sobre la relevancia normativo-legal de la pluralidad lingüística", en VÁZQUEZ, Rodolfo (comp.), Tolerancia y pluralismo, México, Ediciones Coyoacán, 2005 , pp. 235 y ss.

17 Cfr. CARBONELL, Miguel, Los derechos fundamentales en México, México, UNAM-Porrúa, 2005, pp. 979 y ss. 
Durante mucho tiempo se ha supuesto que los derechos lingüísticos corresponden a esa categoría. Considero que no deben mezclarse aspectos como el gobierno de los grupos étnicos, la protección de personas desvalidas, o el reconocimiento de las uniones de homosexuales, por ejemplo, que corresponden a derechos tradicionalmente conculcados, con los derechos que, si bien tuvieron su origen en las omisiones del Estado, hoy forman parte del elenco de derechos que asisten al colectivo de los habitantes.

El derecho a la lengua es de todo. En nuestro caso, el español y las lenguas vernáculas que se hablan en México, forman parte de nuestro patrimonio cultural nacional, y cada persona tiene derecho a la autonomía cultural. Esta forma de autonomía, susceptible de ser ejercida individual o colectivamente, es la que permite que se practique y cultive el idioma libremente escogido, de manera permanente u ocasional. La autonomía cultural de las personas y de los grupos es una expresión más de libertad, sólo posible en el seno de un Estado constitucional. En tanto que supone una decisión sobre el uso de una lengua, tiene efectos de carácter jurídico porque implica, como en toda relación sinalagmática, una serie de obligaciones por parte del ente ante quien se ejerce el derecho. En este caso, la autonomía cultural significa, ante terceras personas, el deber de respeto, y ante los entes públicos, el deber de auxilio.

En este punto debe distinguirse si estamos ante el fenómeno denominado "multiculturalismo". En mi concepto el multiculturalismo corresponde a un ámbito nacional o internacional en el que coexisten diversas expresiones culturales. En el ámbito nacional, empero, lo que se presenta es el pluralismo cultural, porque el mosaico de las culturas es lo que integra la cultura nacional. En el espacio internacional conviven, con igualdad de derecho, las culturas mexicanas, nigeriana o francesa, por ejemplo; pero en el ámbito mexicano no hay una cultura "mexicana" y otra zapoteca o huichol. Todas las expresiones culturales constituyen la cultura mexicana.

El concepto del artículo 2 de la Constitución, en el sentido de que la nación "tiene una composición pluricultural", es equívoco y rezuma una forma velada de exclusión. La suma de todas las formas culturales es lo que constituye la cultura nacional mexicana. De no entenderlo así, entraríamos al debate de saber quiénes son parte de la cultura mexicana y quiénes de las "otras" culturas. Por eso considero que el pluralismo cultural es una característica que enriquece a la cultura mexicana, porque denota versatilidad, libertad e igualdad. Nuestra gran cultura nacional es poliédrica, multifacética, heterogénea, pero igualitaria. No podemos, desde la perspectiva del estado constitucional, decidir que los titulares de la cultura nacional son unos cuantos, o unos muchos, y que los restantes no forman parte de la cultura mexicana sino de una diversa, minoritaria, civilizadamente tolerada, pero ajena a la que, por extraños argumentos, se erige en la única que puede ser considerada como nacional.

La autonomía cultural tendrá que ser reconocida por el Estado, porque de otra suerte carecería de fuerza vinculante. Una vez establecida su base constitucional, serán exigibles acciones positivas por parte del Estado, en cuanto a la protección de las lenguas y la promoción de su desarrollo. Esta obligación, por 
supuesto, no se agotará en el ámbito del territorio nacional. La autonomía cultural de las personas y de los grupos incluye la protección de sus derechos lingüísticos aún cuando, por razones ajenas a su voluntad, se vean obligadas a emigrar del país. Las limitaciones económicas que condicionan el acceso al trabajo e impelen a abandonar el territorio nacional, no deben privar a las personas de sus derechos culturales. A través de convenios internacionales, o de manera directa, el Estado mexicano deberá realizar las acciones positivas que garanticen a los mexicanos el respeto de sus derechos lingüísticos en el extranjero.

ABSTRACT. The present text that is part from the author's speach when achieving the entrance into Mexican Lengua Academy is based on the right of languages. Author will sustain this specific right as part of societies cultural patrimony, as a symbol of groups and men's identity. Also its garantee to achieve it is one more step that constitutionalism has to fill up. 